\title{
The Relationship Between Employee's Status Perception and Organizational Citizenship Behaviors: A Psychological Path of Work Vitality
}

\author{
Yuhao Liu' \\ Xiangzhou Yin ${ }^{2}$ \\ $\mathrm{Si} \mathrm{Li}{ }^{3}$ \\ Xingchi Zhou (1D) \\ Ruilin $\mathrm{Zhu}^{5}$ \\ Fei Zhang ${ }^{4}$ \\ 'School of Management, Huazhong \\ University of Science and Technology, \\ Wuhan, Hubei, People's Republic of \\ China; ${ }^{2} \mathrm{School}$ of Management, Wuhan \\ University of Technology, Wuhan, Hubei, \\ People's Republic of China; ${ }^{3}$ School of \\ Public Administration, Zhongnan \\ University of Economics and Law, Wuhan, \\ Hubei, People's Republic of China; \\ ${ }^{4}$ School of Management, Wuhan Textile \\ University, Wuhan, Hubei, People's \\ Republic of China; ${ }^{5}$ Management School, \\ Lancaster University, Lancaster, UK
}

Purpose: Studies have shown that status-based rankings exist within almost every human social group and influence most aspects of organizational life. However, few studies have discussed the relationship between employees' status and organizational citizenship behaviors (OCBs). Based on social cognitive theory, this paper explores the relationship between employees' status perception and two types of OCBs: challenging and affiliative, as well as the mechanism underlying this relationship by introducing work vitality as the mediator and dominance motivation as the moderator.

Methods: We collected the empirical data from different enterprises located in major cities in China following a two-stage sampling procedure. The final sample consists of 330 employees. Hierarchical multiple regression analysis was used to test the hypothesis.

Results: Employee status perception is positively related to work vitality $(b=0.103, p=$ 0.027), challenging OCBs $(b=0.160, p<0.001)$ and affiliative OCBs $(b=0.105, p=0.006)$. Work vitality mediates the relationship between employee status perception and challenging OCBs with $95 \%$ bias-corrected confidence intervals [0.004, 0.063], and it also mediates the relationship between employee status perception and affiliative OCBs with $95 \%$ biascorrected confidence intervals [0.004, 0.049]. The interaction of status perception and dominance motivation is significantly related to work vitality $(b=0.121, p=0.041)$. Specifically, when dominance motivation is at low level, the effect of status perception on work vitality is -0.008 (non-significant); when dominance motivation is high level, the effect is $0.175(\mathrm{p}=0.005)$.

Conclusion: The result suggests that employees' perceptions of status are positively and significantly related to their challenging and affiliative OCBs, and employee's work vitality mediates this relationship. It further indicates that dominance motivation moderates the relation between status perception and work vitality. Specifically, the positive relationship between employee status perception and work vitality is stronger when an employee has high dominance motivation than low dominance motivation.

Keywords: status perception, work vitality, taking charge behavior, helping behavior, dominance motivation

\section{Introduction}

Correspondence: Xiangzhou Yin School of Management, Wuhan University of Technology, 122 Luosho Road, Wuhan, Hubei, 430070, People's Republic of China Tel $+86 \quad$ I807I 068068

$\mathrm{Fax}+8602787859059$

Email yxzpl@whut.edu.cn
For the past decade, studies of organizational citizenship behaviors have been ubiquitous in the fields of organizational psychology and organizational behaviors. ${ }^{1-4}$ This is unsurprising, as organizations operate in environments that are volatile, uncertain, complex, and ambivalent. ${ }^{5}$ To successfully adapt to such dynamic business environments, 
organizations require their employees to exhibit deep involvement and high commitment to their jobs and organizations. As a result, many studies focus on organizational citizenship behaviors (OCBs), which help organizations to be more adaptive and competitive. ${ }^{6-8}$ Existing studies have found many antecedents or determinants of OCBs such as job satisfaction, ${ }^{9,10}$ job engagement/ embeddedness, ${ }^{11}$ organizational commitment, ${ }^{12,13}$ HR practices, ${ }^{14,15}$ self-efficacy, ${ }^{1,16}$ self-serving motives, ${ }^{17}$ leadership styles. ${ }^{18}$ Noticing that as the research field develops, OCBs are categorized according to their two main functions: affiliative behaviors and challenging behaviors. ${ }^{18,19}$ Affiliative OCBs are behaviors that strengthen relationships in the workplace: they are interpersonal, cooperative, and noncontroversial. A typical affiliative OCB is helping behavior, which studies have identified as having a significant influence on the group and organizational performance. ${ }^{20}$ Challenging OCBs are behaviors that seek to change the status quo and improve an organization. Such behaviors are usually issue-focused and change-oriented. ${ }^{1}$ For instance, taking charge behavior is regarded as a challenging OCB because it "tries to bring change about".,18 Many studies concluded both helping and taking charge behavior as representations of distinct forms of OCBs (affiliative vs challenging) in their research, ${ }^{18,21-23}$ and suggested that capturing these contrasting behaviors is more meaningful and important for research as today's organizations always shift between "stability and change, smooth functioning and discontinuity". ${ }^{24}$ From a contingency perspective, Li et al note that affiliative behaviors exert a positive influence in relatively stable organizational contexts, whereas challenging behaviors are more helpful for organizations in complex and unpredictable environments. ${ }^{18}$ As organizations' business environments can shift over time between stable and unstable states, both affiliative and challenging OCBs are helpful to an organization's survival and success. For this reason, many studies examine both types simultaneously to develop a more holistic view. ${ }^{18,25}$

In this paper, we investigated an employee's self-perceived status which refers to the focal employee's perception of his/ her relative position within an organization or a group. ${ }^{26}$ Studies of the organization and group dynamics begin with the observation that status-based rankings exist within almost every type of human social group, and studies have shown that status influences most aspects of organizational life. ${ }^{27,28}$ However, few studies have discussed the relationship between employees' status and OCBs. The social cognitive theory suggests that an individual's cognition and subsequent behaviors are influenced by their perceptions of their embeddedness in a social system such as an organization or group. ${ }^{29,30}$ In working groups and organizations, employees who perceive themselves as high-status exhibit more confidence in their organizations or groups ${ }^{28}$ which may affect their behaviors. Drawing on social cognitive theory, ${ }^{29}$ this paper discusses the relationship between status and (affiliative and challenging) OCBs and the mechanism that underlies this relationship.

This study aims to investigate the relationship between status perception and two forms of employee OCB (ie, taking charge and helping behaviors), thus filling a gap in the literature. It also uses social cognitive theory to further explore the mechanism linking employee status to OCBs. We introduce work vitality as a mediator between status perception and OCBs. Work vitality is defined as a psychological state in which individuals feel energetic and have great enthusiasm for work. ${ }^{31}$ Porath et al consider work vitality as a positive emotional basis for the psychological experience of personal development. ${ }^{32}$ According to social cognitive theory, individuals' psychological and physiological conditions would influence their assessments of abilities or in other words, self-efficacy. ${ }^{33}$ We argue that high-status members may experience more work vitality and become more proactive and positive in the workplace. Moreover, this paper examines the boundary conditions of the relationship between employee status perception and employee OCBs. Specifically, we argue that dominance motivation - which drives personal striving for status, prestige, and domination within an organization or group - may play an important moderating role in our focal relationship. We argue that dominance motivation serves as an important personal factor in determining individuals' feelings and attitudes toward status perception. Drawing on social cognitive theory, the personal factors would interact with other factors (such as cognitive and environmental factors) and influence people's psychological state. ${ }^{29}$

Our research makes three contributions to the literature. (i) Drawing on social cognitive theory, this paper extends our understanding of employee status by examining the link between status perception and employee OCBs. (ii) We use physiological and psychological perspectives to explore the mechanism that underlies the aforementioned relationship. Specifically, we chose work vitality as the mediator to extend our understanding of the mechanism that mediates the relationship between status perception and OCBs. (iii) We extend the status and achievement motivation literature by exploring and explaining the moderating effect of dominance motivation and the moderated mediation mechanism. The research model is shown in Figure 1. 


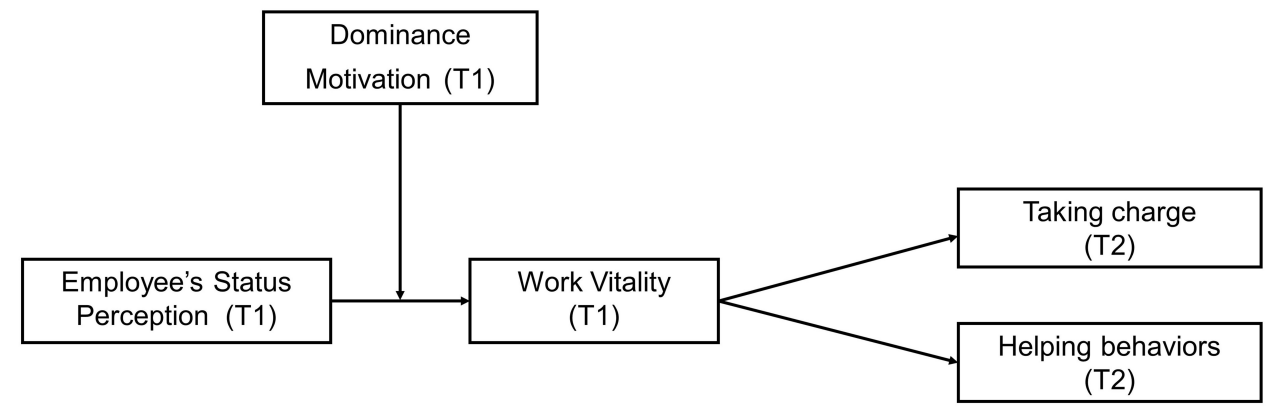

Figure I The theoretical research model.

\section{Literature Review and Hypotheses Employee Status Perception, Taking Charge, and Helping Behaviors}

Considered as one type of the most important behavioral outcomes that benefit the organization, OCBs have been widely studied for the past decade. And the study on OCBs' antecedents has drawn great attention, scholars find that job satisfaction, ${ }^{9,10}$ job engagement/ embeddedness, ${ }^{11}$ organizational commitment, ${ }^{12,13}$ self-efficacy ${ }^{1,16}$ and self-serving motives ${ }^{17}$ are important antecedents of OCBs. Some studies switch focus from personal perspective to organizational perspective and find that human resource practices and leadership styles are also critical determinants of OCBs. ${ }^{14,15,18}$ Although the literatures on the antecedents of OCBs seem to be fruitful and well developed, a large body of these studies only focuses on general forms of OCBs which only focus on self-voluntary and pro-social aspects of such behavior. More recent studies suggest that there are two complementary types of citizenship, namely affiliative OCBs and challenging OCBs. ${ }^{21,23}$ As mentioned, affiliative OCBs are behaviors that focus on building and maintaining relationships in the workplace, while challenging OCBs are behaviors that seek to change the status quo and make improvements for the organization. ${ }^{21}$ In most studies on affiliative and challenging OCBs, the measurement of helping behavior was adopted to assess affiliative OCBs and the measurement of taking charge behavior was used to assess challenging OCBs. ${ }^{22,23}$ Chiaburu et al suggest that affiliative and challenging forms of OCBs reflect prosocial and proactive aspects of citizenship behaviors, ${ }^{22}$ and socio analytic theory supports the idea that employees participate in both forms of OCBs to "fulfill their needs for getting along with and getting ahead of others." The socio analytic perspective of OCBs also relates to the concept of self-perceived status at the workplace which is insufficiently studied in the literature of the antecedents of OCBs.
Employee status perception is an employee's perception and evaluation of his/her relative position within an organization or a group. It usually reflects an individual's non-official status. ${ }^{34}$ Most studies use measures of an individual's prestige, influence, and perceived support in an organization to capture his/her general status. ${ }^{28,35}$ Some studies show that members with high-status perception have a greater sense of self-worth and organizational belonging, ${ }^{36,37}$ and those members also exhibit higher psychological entitlement, self-confidence, and selfesteem. ${ }^{38}$ Other studies show that high status improves individual self-satisfaction and overall social satisfaction. ${ }^{28,34,39}$ Furthermore, when self-needs and social needs are matched and both are satisfied, individuals will consider themselves to be more capable of realizing their expectations and influencing others. ${ }^{40}$

Taking charge behaviors as challenging OCBs are the constructive efforts spontaneously and voluntarily generated by employees to improve work procedures or methods in the workplace. This kind of effort occurs when members are actively thinking about how to perform their tasks and responsibilities more effectively, and how to improve the operational efficiency of the organization. ${ }^{1}$ Studies have found positive relationships between taking charge behavior and many employee outcome variables, such as job satisfaction, organizational commitment, and job performance. ${ }^{41,42}$ Taking charge behavior is also inherently risky for employees because it challenges the status quo of the organization. ${ }^{1}$ Therefore, individuals need to make certain rational cognitive decisions and conduct risk evaluations before deciding whether to engage in taking charge behavior. ${ }^{21}$

According to social cognitive theory, individuals' behaviors are shaped and determined by the constant interaction of environmental, cognitive, and behavioral factors. ${ }^{43}$ The environmental factors are social norms, cultures, and influences on others; the cognitive factors are knowledge, 
expectations, and attitudes; and the behavioral factors are skills, practice, and self-efficacy. ${ }^{29}$ Thus, we propose that status perception can influence employees' behaviors in their organizations.

Prior research has established that employees with highstatus perception consider themselves being able to access more organizational resources and are more influential. ${ }^{26}$ These resources can be tangible, such as material resources, or intangible, such as power, relationships, and psychological resources. Therefore, employees who perceived themselves as high status have a strong sense of control and feel more capable of influencing others. At the same time, not only do they feel respected, praised, and helped by others but are also likely to expect such treatment; in other words, they hold positive expectations about others' responses and conduct toward them. As a result, they usually show more trust in others and worry less than low-status employees about the risk of challenging the organizational status quo (eg, taking charge behaviors). Furthermore, the resources and social support associated with high status can increase an individual's positive cognitions, such as self-efficacy beliefs and expectations about conducting OCBs. ${ }^{44,45}$ Fuller et al find that if employees are given high organizational status in the organization, they will be more proactive in organizationsupportive behaviors and will focus more on constructive change. ${ }^{46}$ Furthermore, high-status members can handle the risks of taking charge better than others due to their advantageous social position in the group. Combining the previous arguments, we argue that self-perceived status is a cognitivemotivational state that facilitates taking charge of behaviors.

A similar argument can explain the influence of highstatus perception on employee helping behaviors. Employee helping behaviors refer to employees' voluntarily helping others to avoid work errors and solve work problems. ${ }^{20}$ Deng et al suggest that high-status individuals may engage in more helping behaviors to maintain a good image. ${ }^{47}$ Many studies show that helping colleagues not only improves personal image but also brings in additional benefits. For instance, Bolino finds that helping leads to positive feedback from the leader. ${ }^{48}$ Clary and Snyder find that employees with more helping behaviors achieve more in their careers. ${ }^{49}$ Nowak's study shows that people are prone to help those who have helped them. ${ }^{50}$ Lount and Pettit find that individuals with perceived high-status are more likely to be generous to others and to gain more trust than others. ${ }^{51}$ Therefore, individuals with perceived highstatus are more willing to help others to obtain highquality reciprocal relationships, ${ }^{47,52}$ which will further consolidate their high status. Other studies show that highstatus members have higher external social expectations ${ }^{53}$ and that their views are more easily accepted and praised by others. ${ }^{47}$ Therefore, individuals with perceived high status tend to believe that their help behaviors will be accepted and are more willing to actively show their kindness and to accept care from others in return. ${ }^{54,55}$ According to the above discussion, we posit that:

Hypothesis 1a: Employee's Status perception is positively related to taking charge.

Hypothesis 1b: Employee's Status perception is positively related to helping behavior.

\section{The Mediating Role of Work Vitality}

Work vitality refers to a positive feeling that one has sufficient energy at work. ${ }^{31}$ Individuals with high work vitality usually feel alive and energized, and they approach life with energy, enthusiasm, vigor, and excitement. They always do things wholeheartedly and will stick with a job to the end. ${ }^{56}$ Spreitzer et al suggest that when individuals perceive that they have control over and are capable of mastering the challenges at work, they will experience vitality and will thrive at work. ${ }^{31}$ Positive social factors, such as high-quality connections, are important antecedents of vitality. ${ }^{57}$ A positive social environment normally provides people with important and positive psychological effects (eg, psychological safety) that trigger a feeling of vitality. ${ }^{56,58}$ According to Spreitzer et al's work, positive relational resources increase an employee's sense of agency, which will lead to individual development and vitality. ${ }^{31}$ Moreover, many studies have linked social resources to physiological changes in the neuroendocrine, cardiovascular, and immune systems. ${ }^{59,60}$ These physiological factors influence an individual's openness to experience and enhance their capacity to act, ${ }^{61}$ factors that are closely related to work vitality. Thus, individuals with perceived high status are more likely to have positive social resources, ${ }^{36,37,40}$ which promote positive physiological and psychological experiences and eventually lead to greater work vitality.

According to social cognitive theory, individuals rely on psychological and physiological conditions to assess their abilities and then engage in targeted behaviors. ${ }^{33}$ As work vitality consists of both positive psychological and physiological experiences, it is an important factor in their behaviors. Individuals with high work vitality experience a psychological state of aliveness, they feel that their actions in life and at work are more meaningful and purposeful, they have positive expectations about the future, and they feel great about their physical circumstances. ${ }^{56,62}$ Such employees usually feel 
more confident and have greater self-efficacy and work embeddedness, which leads to creative solutions to work issues and improvements in job performance. ${ }^{63,64}$ Energetic employees usually display agile thinking, strong work motivation, high work efficiency, ${ }^{65}$ and a high level of job embeddedness. ${ }^{32}$ In a recent meta-analysis, Kleine et al find that work vitality correlates significantly and positively with creative performance. ${ }^{66}$ As extra-role behaviors that challenge the status quo, taking charge behaviors are similar to creative and innovative behaviors, such as problem-solving. ${ }^{67}$ Therefore, we posit that employees with high work vitality are more energized to resolve work issues and more capable of engaging in taking charge behaviors.

Besides, as vitality is a reinforcing experience, individuals try to "enhance, prolong, or reenact the circumstances they perceive as increasing their vital energy",56 and try to avoid negative situations that diminish their vitality. That is, when employees feel vitality at work, they want to maintain the positive affect and motivation, and thus tend to enhance, prolong, or reenact the supportive circumstances by engaging in pro-social acts, which make them feel better. Studies have also shown that employees with positive affect and emotions usually empathize with and provide emotional support to others. ${ }^{68}$ Accordingly, we posit that high vitality employees are more inclined to help others. Drawing on the above discussion, we hypothesize that:

Hypothesis 2a: Work vitality mediates the positive relationship between status perception and taking charge.

Hypothesis 2b: Work vitality mediates the positive relationship between status perception and helping behavior.

\section{The Moderating Role of Dominance Motivation}

The unequal distribution of power and resources is common in human societies and leads to hierarchical power structures. ${ }^{69,70}$ In various social groups, such structures become solidified over time, "making it increasingly difficult for subordinates to change their social status and to access valuable resources or prestige". ${ }^{71}$ Accordingly, individuals may on the one hand advocate for equality to avoid social harm and deal with cognitive dissonance caused by inequality. ${ }^{72}$ On the other hand, they may be motivated to attain advantageous social positions (high status) and become dominant. ${ }^{73,74}$ Social psychology scholars suggest that people possess various domain-specific motivations that guide different human behaviors. ${ }^{75}$ Maner and Mead suggest that dominance motivation is an important factor in individuals' desire to attain and use power and in maintaining social hierarchies. ${ }^{76}$ According to social cognitive theory, the interaction of individuals' cognition and personal factors influence their psychological state. ${ }^{29}$

In this paper, we argue that dominance motivation plays an important role in determining individuals' feelings and attitudes toward status perception. Individuals with greater dominance motivation are more eager to attain high social status. ${ }^{77}$ Furthermore, the high status will give individuals access to abundant tangible and intangible resources and social respect. ${ }^{77,78}$ When individuals' dominance motivation is high, they care more about attaining the resources and power that are related to high status. $^{79}$ In this case, perceived high status will make individuals with high dominance motivation more satisfied and lead to a more positive affect and greater vitality. ${ }^{32}$ Moreover, as individuals who are high in dominance motivation are more aware of their status, they are able to perceive when their status is high and feel satisfied that they have achieved the goal of a better position in the group hierarchy. Prior research shows that achievement motivation is significantly related to people's physical and psychological well-being. ${ }^{80}$ Thereby, as a subset of achievement motivation, dominance motivation will bring pleasant feelings and positive outcomes to individuals when it is fulfilled. ${ }^{81}$ It will also further strengthen the relationship between perception of status and work vitality. In contrast, when individuals are low in dominance motivation, the positive relationship between status perception and vitality might be weaker or even non-significant because these individuals are not strongly motivated to gain higher social status. Accordingly, we argue that highstatus individuals are more likely to experience vitality at work when their innate dominance motivation is high, and low-dominance motivation individuals may not enjoy the advantages of perceived high status as much as highdominance individuals. Thus, we hypothesize as follows:

Hypothesis 3: Dominance motivation moderates the relationship between employee's status perception and work vitality; such that when dominance motivation is high, the positive relationship between employee's status perception and work vitality is stronger, and vice versa.

Taking these findings as a whole, we can infer that dominance motivation moderates the relationship between perception of status and work vitality, and thus affects individuals' helping and taking charge behaviors. 
Specifically, in individuals with high dominance motivation, perception of high status will be better translated into work vitality, which will positively affect their behaviors. Accordingly, the hypothesizes we posit are presented as follows:

Hypothesis 4a: Dominance motivation moderates the mediation effect of work vitality on the relationship between employee's status perception and taking charge; such that when dominance motivation is high, the mediation effect will be stronger, and vice versa.

Hypothesis 4b: Dominance motivation moderates the mediation effect of work vitality on the relationship between employee's status perception and helping behavior; such that when dominance motivation is high, the mediation effect will be stronger, and vice versa.

\section{Method}

\section{Sample and Procedures}

We collected data from different companies located in major cities in China. To maximize the generalizability of our results, the companies were selected from various industries, including manufacturing, IT, real estate, biotechnology, and the healthcare industry. We sealed the survey questionnaires in envelopes and mailed them to the HR departments of the selected companies. A time-lagged technique was used in this study to reduce common method bias, as scholars suggested that this may "reduce the salience of the predictor variable or its accessibility in memory". ${ }^{82}$ The HR departments helped us to collect two waves of data at a two-month interval. In the first round of data collection, the participants were asked to report their status perception, dominance motivation, work vitality, and demographic data. In the second round of data collection, they were asked to report their taking charge and helping behaviors.

We distributed 1000 questionnaires in the first round of data collection and received 560 back, giving a 56\% response rate. In the second round, 365 out of the 560 questionnaires were returned, yielding a response rate of $65 \%$. After dropping responses with missing data and a few invalid questionnaires (eg, had the same answer for every survey question), our final sample consisted of 330 participants. In the final sample, $61 \%$ were male and $39 \%$ were female. Their average age was 31 years, $83 \%$ were between 22 and 35 years old, $65 \%$ had 3 -year college degrees or above, $35 \%$ had a high school education or below, and their average length of organizational tenure was 8 years.

\section{Measurement Scales and Analysis Tools}

All scales we used in the current research came from the English version originally. Given the fact that the research was conducted in China, we followed a "Translation and Back-translation procedure" that was widely applied to various cross-cultural studies, and all scales were translated to adapt to the Chinese language environments. ${ }^{83}$ All variables were measured on five-point Likert scales where $1=$ strongly disagree, $5=$ strongly agree.

Status perception (T1). Employee's perception of selfstatus was measured following Janssen and Gao's threeitem scale measurement. ${ }^{26}$ Sample item as "I have a lot of status within the team". All ratings were on a 5-point Likert scale ranging from 1 to 5 as above mentioned (Cronbach's $\alpha=0.765$ ).

Work vitality (T1). A four-item scale adapted from Spreitzer et al's work was used to measure an employee's sense of work vitality. ${ }^{84}$ Sample items were "I feel alive and vital" and "I am looking forward to each new day" (Cronbach's $\alpha=0.861$ ).

Dominance motivation (T1). Four items were adapted from Cassidy and Lynn's work to measure employee's dominance motivation. ${ }^{81}$ Sample items included "If given the chance I would make a good leader of people" and "I like to give orders and get things going" (Cronbach's $\alpha=$ 0.746).

Taking charge behaviors (T2). We adopted Morrison and Phelps's ten-item scale to measure employees' taking charge behaviors. ${ }^{1}$ A sample item was "I try to bring about improved procedures for the work unit or department" (Cronbach's $\alpha=0.905$ ).

Helping behaviors (T2). A Three-item scale revised from Lee et al's study was used to measure employee's proactive helping behaviors. ${ }^{85}$ A sample item was "Without being asked, today I helped coworkers avoid potential problems with their work" (Cronbach's $\alpha=0.759$ ).

Control variables (T1). The demographic variables were controlled in our analysis following the suggestions of other organizational behavior studies that investigating employee's OCBs, such as taking charge. ${ }^{1,86}$ Therefore, gender $(2=$ female, $1=$ male), age (in years), education level $(1=$ high school or below, 2 = associate's degree, $3=$ bachelor's degree, $4=$ master's degree, $5=$ doctoral degree) and work tenure (in years) were included as control variables. 


\section{Results}

Confirmatory Factor Analyses, Descriptive Statistics, and Correlations

In order to make further analysis, a CFA (confirmatory factor analysis) must be done to examine the discriminant validity of the research variables. We used Mplus 7.4 to run the CFA and first assessed a five-factor model for all variables including status perception, work vitality, taking charge, helping behaviors, and dominance motivation. We applied correlations between error terms according to item content. ${ }^{87}$ By allowing four correlations between items of taking charge, one correlation between items of the work vitality, and one correlation between items of the dominance motivation, we achieved an acceptable model fit. The fivefactor model's fit indexes: $\chi^{2}=557.131$; $\mathrm{df}=236$; CFI $=$ $0.916 ;$ TLI $=0.901 ;$ RMSEA $=0.064 ;$ SRMR $=0.068$. Then, we combined variables collected in $\mathrm{T} 1$ and run a three-factor analysis, the indexes are $\chi^{2}=1095.119 ; \mathrm{df}=243$; CFI $=$ $0.776 ; \mathrm{TLI}=0.745 ; \mathrm{RMSEA}=0.103 ; \mathrm{SRMR}=0.113$. After analyzing the three-factor, we combined variables collected in T2 and analyze the two-factor model; In the end, we combined all variables into a one-factor model and run the CFA analysis. Table 1 shows the CFA results after we applied correlations between error terms, these results indicate that the five-factor model has the best fit and is appropriate for further analysis. Following Podsakoff et al's work, we also conducted Harman's one-factor analysis to test for common method variance. ${ }^{82}$ The results show that the variance of the first factor explains $30.95 \%$ of the total variance (smaller than the $40 \%$ threshold), indicating that the fit of Harman's one-factor analysis is unacceptable. ${ }^{88}$ In other words, our data do not suffer from common method variance. The descriptive statistics, inter-correlations for the research variables are also shown in Table 2 as follows.

\section{Hypothesis Testing}

To test our hypothesis, we first used hierarchical multiple regression and then used the bootstrapping and regression method developed by Hayes to further check the moderated mediation effect. ${ }^{89}$ As we can see from Table 3 which we set work vitality as the dependent variable for hierarchical multiple regression analysis, employee status perception is significantly related to work vitality $(b=0.103, p=0.027)$, and the interaction of status perception and dominance motivation are significantly related to work vitality $(b=0.121, p=$ $0.041)$. These results provide a promising supportive signal to further analyze the mediation and moderation effect.

Table 4 presents the results of hierarchical multiple regression analysis for taking charge as the dependent variable. As shown, status perception is positively related to taking charge behaviors significantly $(b=0.160, p<$ 0.001 ), which supports hypothesis $1 \mathrm{a}$. Table 5 presents the results of setting helping behaviors as the dependent variable. The status perception is also significantly related to helping ( $b=0.105, p=0.006$ ), which supports hypothesis $1 \mathrm{~b}$.

To check the mediation effect, work vitality is significantly related to taking charge when we entered all the variables $(b=0.268, p<0.001)$ as Table 4 shows, which provides support for hypothesis 2a from Baron and Kenny's method. ${ }^{90}$ Work vitality is also significantly related to helping when all the variables were entered $(b=0.210, p<0.001)$ as Table 5 shows, which provides potential support for hypothesis $2 \mathrm{~b}$. To ensure the mediation effect, we run the mediation analysis alone following Hayes's work to give more confident support of our hypotheses $2 \mathrm{a}$ and $2 \mathrm{~b} .{ }^{91}$ The results show that the mediation effect of work vitality is significant $(95 \% \mathrm{CI}$ is [0.004, 0.063] and [0.004, 0.049], respectively). Combining with the previous analysis, we can infer that the hypothesis $2 \mathrm{a}$ and $2 \mathrm{~b}$ are supported.

To check the moderating effect, the results of model 3 in Table 3 show that the interaction of dominance motivation and status perception is significantly related to work vitality $(b=0.121, p=0.041)$. Specifically, when dominance motivation is at a low level (-sd), the effect of status perception on work vitality is -0.008 (n.s.); when dominance motivation is high level ( + sd), the effect is $0.175(p=0.005)$. Thus hypothesis 3 is supported.

Table I Results of Confirmatory Factor Analysis

\begin{tabular}{|l|c|c|c|c|c|c|c|}
\hline Model & CMIN & DF & RMSEA & SRMR & CFI & TLI & CMIN/DF \\
\hline One factor model: SP + WV + TC + HB + DM & 1383.492 & 246 & 0.119 & 0.104 & 0.701 & 0.664 & 5.624 \\
Two factor model: SP + WV + DM, TC + HB & 1262.849 & 245 & 0.112 & 0.118 & 0.732 & 0.698 & 5.154 \\
Three factor model: SP +DM+WV, TC, HB & 1095.119 & 243 & 0.103 & 0.113 & 0.776 & 0.745 & 4.507 \\
Five factor model: SP, WV, TC, HB, DM & 557.131 & 236 & 0.064 & 0.068 & 0.916 & 0.901 & 2.361 \\
\hline
\end{tabular}

Abbreviations: SP, status perception; WV, work vitality; TC, taking charge; HB, helping behavior; DM, dominance motivation; CMIN, Chi-square; DF, degree of freedom; RMSEA, root-mean-square error of approximation; SRMR, standardized root mean square residual; CFI, comparative fit index; TLI, Tucker-Lewis index. 
Table 2 Descriptive Statistics and Correlations

\begin{tabular}{|c|c|c|c|c|c|c|c|c|c|c|c|}
\hline Variable & Mean & SD & $\mathbf{I}$ & 2 & 3 & 4 & 5 & 6 & 7 & 8 & 9 \\
\hline I. Gender & 1.390 & 0.489 & I & & & & & & & & \\
\hline 2. Age & 30.680 & 6.595 & -0.008 & I & & & & & & & \\
\hline 3. Education & 2.720 & 0.707 & 0.017 & -0.032 & 1 & & & & & & \\
\hline 4. Tenue & 7.940 & 6.663 & -0.014 & $0.967 * *$ & $-0.232 * *$ & 1 & & & & & \\
\hline 5. Status perception & 2.725 & 0.938 & $-0.178 * *$ & 0.056 & -0.010 & 0.042 & I & & & & \\
\hline 6. Work vitality & 3.756 & 0.785 & $-0.177 * *$ & -0.017 & 0.006 & -0.017 & $0.149 * *$ & 1 & & & \\
\hline 7. Taking charge & 3.388 & 0.666 & $-0.170 * *$ & $0.116 *$ & -0.019 & 0.105 & $0.254 * *$ & $0.356 * *$ & I & & \\
\hline 8. Helping behavior & 3.889 & 0.650 & $-0.147 * *$ & $0.162 * *$ & 0.003 & $0.149 * *$ & $0.184 * *$ & $0.284 * *$ & $0.430 * *$ & 1 & \\
\hline 9. Dominance Motivation & 2.820 & $0.75 I$ & $-0.201 * *$ & 0.007 & -0.012 & 0.017 & $0.298 * *$ & $-0.112^{*}$ & $0.429 * *$ & $0.254 * *$ & I \\
\hline
\end{tabular}

Notes: $*_{p}<0.05, * *_{p}<0.01$ (two tailed).

Table 3 Regression Analyses for Work Vitality

\begin{tabular}{|c|c|c|c|c|c|c|}
\hline \multirow[t]{3}{*}{ Predictor Variables } & \multicolumn{6}{|c|}{ Work Vitality } \\
\hline & \multicolumn{2}{|c|}{ Model I } & \multicolumn{2}{|c|}{ Model 2} & \multicolumn{2}{|c|}{ Model 3} \\
\hline & b & SE & b & SE & b & SE \\
\hline \multicolumn{7}{|l|}{ Control } \\
\hline Gender & $-0.249 * * *$ & 0.089 & $-0.237 * * *$ & 0.090 & $-0.237^{* *}$ & 0.088 \\
\hline Age & -0.007 & 0.040 & -0.004 & 0.040 & -0.009 & 0.042 \\
\hline Education & 0.018 & 0.097 & 0.013 & 0.097 & 0.030 & 0.106 \\
\hline Tenue & 0.004 & 0.040 & 0.002 & 0.040 & 0.006 & 0.042 \\
\hline \multicolumn{7}{|l|}{ Independent variable } \\
\hline Status perception & $0.103 *$ & 0.046 & 0.091 & 0.048 & -0.259 & 0.184 \\
\hline \multicolumn{7}{|l|}{ Moderator } \\
\hline Dominance Motivation & & & 0.053 & 0.060 & -0.285 & 0.167 \\
\hline \multicolumn{7}{|l|}{ Interaction } \\
\hline Status perception $\times$ Dominance Motivation & & & & & $0.121 *$ & 0.059 \\
\hline
\end{tabular}

Notes: $*_{p}<0.05,{ }^{*} p<0.01, *_{* *} p<0.001$ (two tailed).

Table 4 Regression Analyses for Taking Charge

\begin{tabular}{|c|c|c|c|c|c|c|}
\hline \multirow[t]{3}{*}{ Predictor Variables } & \multicolumn{6}{|c|}{ Taking Charge } \\
\hline & \multicolumn{2}{|c|}{ Model 4} & \multicolumn{2}{|c|}{ Model 5} & \multicolumn{2}{|c|}{ Model 6} \\
\hline & b & SE & b & SE & b & SE \\
\hline \multicolumn{7}{|l|}{ Control } \\
\hline Gender & $-0.176^{*}$ & 0.073 & $-0.150 *$ & 0.071 & -0.109 & 0.070 \\
\hline Age & 0.008 & 0.033 & 0.022 & 0.032 & 0.010 & 0.031 \\
\hline Education & 0.031 & $0.08 I$ & 0.004 & 0.077 & 0.026 & 0.076 \\
\hline Tenue & 0.003 & 0.033 & -0.010 & 0.032 & 0.001 & 0.032 \\
\hline \multicolumn{7}{|l|}{ Independent variable } \\
\hline Status perception & $0.160 * * *$ & 0.039 & & & $0.133^{* * * *}$ & 0.037 \\
\hline \multicolumn{7}{|l|}{ Mediator } \\
\hline Work vitality & & & $0.287^{* * *}$ & 0.044 & $0.268^{* * *}$ & 0.044 \\
\hline
\end{tabular}

Notes: $*_{p}<0.05, * * *_{p}<0.001$ (two tailed). 
Table 5 Regression Analyses for Helping Behavior

\begin{tabular}{|c|c|c|c|c|c|c|}
\hline \multirow[t]{3}{*}{ Predictor Variables } & \multicolumn{6}{|c|}{ Helping Behaviors } \\
\hline & \multicolumn{2}{|c|}{ Model 7} & \multicolumn{2}{|c|}{ Model 8} & \multicolumn{2}{|c|}{ Model 9} \\
\hline & b & SE & b & SE & b & SE \\
\hline \multicolumn{7}{|l|}{ Control } \\
\hline Gender & $-0.159 *$ & 0.072 & -0.131 & 0.070 & -0.106 & 0.071 \\
\hline Age & 0.032 & 0.032 & 0.040 & 0.031 & 0.033 & 0.031 \\
\hline Education & -0.021 & 0.079 & -0.039 & 0.077 & -0.025 & 0.077 \\
\hline Tenue & -0.017 & 0.033 & -0.025 & 0.032 & -0.018 & 0.032 \\
\hline \multicolumn{7}{|l|}{ Independent variable } \\
\hline Status perception & $0.105^{* *}$ & 0.038 & & & $0.083 *$ & 0.037 \\
\hline \multicolumn{7}{|l|}{ Mediator } \\
\hline Work vitality & & & $0.222 * * *$ & 0.044 & $0.210 * * *$ & 0.044 \\
\hline
\end{tabular}

Notes: ${ }^{*} p<0.05,{ }^{* *} p<0.01$, ${ }^{* * *} p<0.001$ (two tailed).

To further test our research model, we used the PROCESS macro of SPSS developed by Hayes to do more analysis. ${ }^{89}$ We also set a bootstrapping sample of 5000 for the regression analysis and the significance of the effect we tested was computed based on bias-corrected confidence intervals. Tables 6 and 7 includes the results of regressions testing hypotheses $4 \mathrm{a}$ and $4 \mathrm{~b}$.

For testing taking charge behaviors as the dependent variable, the $95 \% \mathrm{CI}$ of total moderated mediation effect is [0.001, 0.075], indicating a significant moderated mediation effect. More specifically, as Table 6 shown, the indirect effect which represents the mediation effect of work vitality on the relationship between status perception and taking charge behaviors is significant when dominance motivation is at a high level $(b=0.047,95 \% \mathrm{CI}$ is $[0.012,0.092])$, and non-significant when dominance motivation is at a low level $(b=-0.002,95 \% \mathrm{CI}$ is $[-0.044$, 0.036]). Therefore, hypothesis $4 \mathrm{a}$ is supported.

For testing helping behaviors as the dependent variable, the $95 \% \mathrm{CI}$ of total moderated mediation effect is [0.002, $0.062]$, indicating a significant moderated mediation effect. More specifically, as Table 7 shown, the indirect effect which represents the mediation effect of work vitality on the relationship between status perception and helping behaviors is significant when dominance motivation is at a high level $(b=$ $0.037,95 \% \mathrm{CI}$ is $[0.009,0.076])$, and non-significant when dominance motivation is at a low level $(b=-0.002,95 \% \mathrm{CI}$ is $[-0.038,0.026])$. Accordingly, hypothesis $4 \mathrm{~b}$ is supported. The interaction effect of status perception and dominance motivation on work vitality is shown in Figure 2.
Table 6 Moderated Regression Analyses with Bootstrapping by SPSS PROCESS (Taking Charge as Outcome)

\begin{tabular}{|l|c|c|c|c|c|}
\hline \multicolumn{1}{|c|}{ Conditional Indirect Effect At Specific Values of Dominance } \\
Motivation \\
\hline Moderator & Level & \multicolumn{4}{|c|}{ Taking Charge } \\
\hline & & $\begin{array}{c}\text { Conditional } \\
\text { Indirect } \\
\text { Effect }\end{array}$ & SE & \multicolumn{2}{|c|}{$\begin{array}{c}\text { Bias- } \\
\text { Corrected } \\
95 \% \text { Cl }\end{array}$} \\
\hline $\begin{array}{l}\text { Dominance } \\
\text { motivation }\end{array}$ & Low & -0.002 & 0.020 & -0.044 & 0.036 \\
\cline { 2 - 6 } & High & 0.047 & 0.021 & 0.012 & 0.092 \\
\hline
\end{tabular}

Table 7 Moderated Regression Analyses with Bootstrapping by SPSS PROCESS (Helping Behavior as Outcome)

\begin{tabular}{|l|c|c|c|c|c|}
\hline \multicolumn{5}{|c|}{ Conditional Indirect Effect at Specific Values of Dominance } \\
Motivation \\
\hline Moderator & Level & \multicolumn{4}{|c|}{ Helping Behavior } \\
\hline \multirow{2}{*}{$\begin{array}{l}\text { Dominance } \\
\text { motivation }\end{array}$} & Low & $\begin{array}{c}\text { Conditional } \\
\text { Indirect } \\
\text { Effect }\end{array}$ & SE & \multicolumn{2}{|c|}{$\begin{array}{c}\text { Bias- } \\
\text { Corrected } \\
95 \% \text { Cl }\end{array}$} \\
\cline { 2 - 6 } & High & -0.002 & 0.016 & -0.038 & 0.026 \\
\hline
\end{tabular}

\section{Discussion}

Based on social cognitive theory, this paper proposed a theoretical model explicating the relationship between employee status perception and OCBs (ie, taking charge and helping behaviors), as well as the mediation effect and 


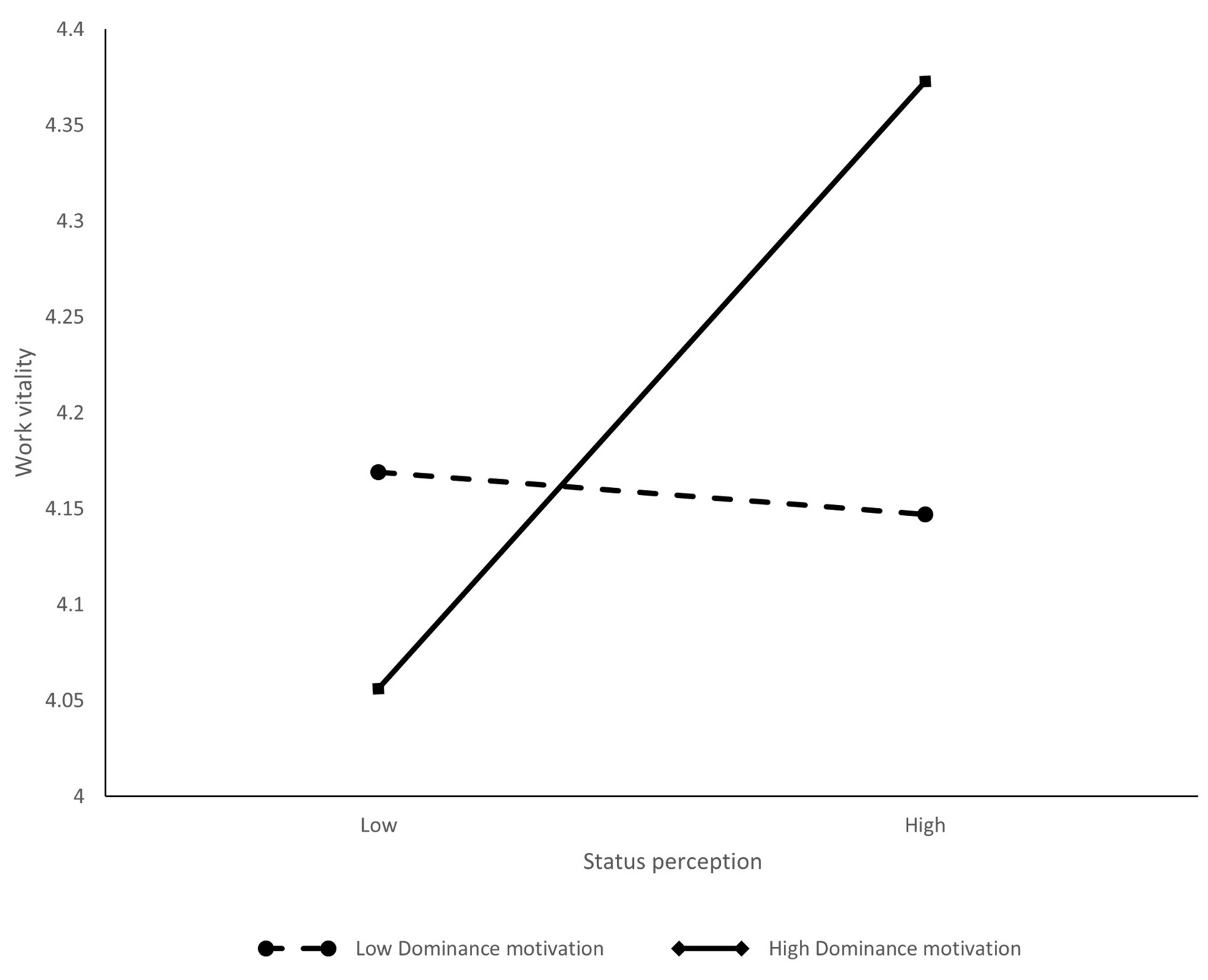

Figure 2 Interaction effect of perceived status and dominance motivation on work vitality.

boundary condition. We collected two-wave time-lagged data from enterprises in mainland China to test the model. The results show that status perception is positively related to both taking charge and helping behaviors and work vitality serves as a mediator. Moreover, Employees' dominance motivation moderates the relationships between status perception and taking charge/helping behaviors and the mediating effect of work vitality for these relationships. When dominance motivation is high, the positive relationships and their mediating mechanism are stronger.

\section{Theoretical Contribution}

Our research makes three contributions. First, we test the influence of employees' status perception on the two types of organizational citizenship behaviors: challenging and affiliative OCBs. Previous studies have shown a link between status and employee citizenship or proactive behaviors, ${ }^{26,47}$ but there are few studies disentangle the relationship between status perception and these two types of OCBs. From a more holistic perspective, we use taking charge and helping behaviors as representations of employees' OCBs. Social cognitive theory suggests that there is a "triadic reciprocal causation" between behavioral, cognitive and environmental factors, it also emphasis that individual's induced beliefs on his/her controllability and capability would strongly affect the self-regulatory process and behavior. Drawing on this social cognitive perspective, this study extends the relevant literatures by disentangling the relationship between employee status perception and OCBs. As H1a and $\mathrm{H} 1 \mathrm{~b}$ are supported in our empirical study, we suggest that increasing employee's status perception may help improve their sense of control in their work and thereby increase their OCBs. 
Second, this study explores how work vitality mediates the relationship between employees' status perception and OCBs. Although some scholars have examined the relationship between status and proactive behaviors, ${ }^{26,47}$ the mediating mechanism remains unclear. Studies that link individual physiological changes to the neuroendocrine, cardiovascular, and immune systems to social factors such as status, resources, and relationships ${ }^{59,60}$ have led organizational researchers to study the role of physiological factors in workplace behaviors. These physiological factors have been found to influence an individual's openness to experience and an enhanced capacity to act, ${ }^{61}$ which are closely related to work vitality. Our paper combines the physiological perspective with the psychological perspective and tests work vitality as a mediating variable between status perception and OCBs. Based social cognitive theory, we open the black box of the mechanism that links status perception to OCBs. As $\mathrm{H} 2 \mathrm{a}$ and $\mathrm{H} 2 \mathrm{~b}$ get supported, our study extends the literatures of social cognitive theory by suggesting that positive beliefs about one's ability can also energize the employee physiologically while previous studies primarily focus on selfefficacy perceptions.

Third, our research also explores the boundary condition for the relationship between employee status perception and OCBs and the interactive effect of dominance motivation and status perception on work vitality. As mentioned above, when dominance motivation serves as a basic and vital social hierarchy navigation strategy for an individual, he/she will be particularly invested in endorsing ideologies that justify the hierarchical structure. ${ }^{71}$ Thus, when people's dominance motivation is high, the positive relationship between their status perception and work vitality is more salient, as is the indirect relationship between status perception and OCBs via work vitality. As $\mathrm{H} 3, \mathrm{H} 4 \mathrm{a}$ and $\mathrm{H} 4 \mathrm{~b}$ get supported in this study, the results show that the interaction of individuals' goal motivation and status perception are fairly important as social cognitive theory suggests.

\section{Practical Implication}

For organizations and group leaders that wish to promote organizational citizenship behaviors, this paper provides three suggestions. First, organizations and group leaders need to facilitate appropriate social hierarchies within organizations or groups. Although today's organizations promote flat and flexible structures, this does not mean that there are no social hierarchies or that employees have no sense of their relative position and status within an organization or group. When organizations and group leaders appreciate employees' suggestions and ideas, this may increase those employees' perceptions of their status. In addition, leaders should consider sharing more power, resources, and responsibilities with appropriate employees, as this will increase the employees' perceived status and hence their OCBs.

Second, our research shows that the positive relationship between status perception and OCBs via work vitality is only significant when an individual's dominance motivation is high. This means that the suggestions given above for promoting employees' status might not work all the time. Leaders must determine which employees are most likely to engage in more OCBs once they have attained higher status. Moreover, when leaders promote individuals with high dominance motivation, they should make sure that the organization's procedures emphasize justice and fairness. Leaders always need to control how such employees acquire and use power. When leaders promote individuals with low dominance motivation, they must make sure that they are motivated to work and that they will fulfill their responsibilities as high-status members of the organization. Also, it would be useful to provide them with appropriate leadership training.

Third, as the results show that work vitality can indirectly promote challenging and affiliative OCBs, leaders can adopt management practices that boost employees' feelings of vitality and motivation. For example, management could gamify certain organizational procedures or introduce challenging but non-work-related activities. Such practices may increase employees' work vitality and eventually improve organizational or group outcomes.

Finally, it is important to avoid bias in personnel practices such as hiring, selecting or prompting talents. The results of our research model suggest that there is no significant influence of dispositional factors such as gender, age, education and tenure that on employee OCBs. Also as mentioned, employees with either high or low dominance motivation can explicit their value when they are embedded in the right working context.

\section{Limitation and Future Directions}

The current study has some limitations, which could be considered in future studies. First, although we use a twowave time-lagged data collection strategy, which may address some of the concerns about the causal relationships between our variables, the sample still suffers from 
the same source issue. Although, Carpenter et al's work suggests that the mean difference between self-raters and other-raters on OCBs is rather small. ${ }^{92}$ In the future, we need to consider multiple sources for the ratings.

Second, previous studies have treated work vitality and learning as components of thriving at work. ${ }^{31,66}$ This study only discusses work vitality as a major positive psychological state for employees because vitality is an affective experience and positive energy is more direct and fundamental to individuals' emotional experience. It would be worthwhile to explore whether perceived self-status influences employees' positive attitude toward learning at work and thus affects their behavioral outcomes. "Learning" entails individuals' positive feelings about acquiring and applying knowledge and skills. ${ }^{31}$ High-status employees may feel more capable of acquiring knowledge because of their easy access to more resources, but they also show low motivation to gain and use some types of knowledge and skills, as they have already attained high social status. Future studies should explore the mediating mechanism and boundary conditions of this relationship.

Third, this study draws on motivation theory to examine the moderating effect of personal dominance motivation. According to the literature, there are different types of achievement motivations, such as prestige motivation. It would be interesting for future studies to test the influence of other types of achievement motivations.

Fourth, although social cognitive theory explains the interaction of internal and external factors that drive individual's behaviors, ${ }^{93}$ which would provide good theoretical foundation on our research model. Switching theoretical perspective may still help us to better understand how status influence employee's different behaviors. For example, from identity perspective, employees' status perception may affect the formation of identities based on social hierarchies or work positions and then lead to behaviors that highly related to certain identity. From social exchange perspective, higher status perception may signify higher exchange qualities with leaders and coworkers which will lead to more proactive and trust-based behaviors. Thus, it's worthwhile to take different theoretical perspective or lens to look at the relationship between status perception and sequent behavioral outcomes.

\section{Conclusion}

This study explores how perceived employee status affects two different OCBs: helping behavior, an affiliative OCB, and taking charge, a challenging OCB. We introduce work vitality as an important mediator and dominance motivation as the moderator. The results show that employee status perception is positively related to both helping and taking charge behaviors. This relationship is mediated by work vitality, and dominance motivation strengthens the mediation effect.

The contributions of this study can be summarized as follows. First, this paper examines the relationship between employee status perception and two different types of employee OCBs. Second, we identify the mechanism of that relationship by theorizing the mediating effect of work vitality. Third, we explore the boundary condition of the relationship between status perception and OCBs via work vitality.

\section{Ethical Statement}

This study was approved by the Ethics Committee on Human Experimentation of Wuhan Textile University and complied with the Declaration of Helsinki. The written informed consent form and an introduction of the purpose of our survey research were provided to all participants together with the questionnaires. We explained to the participators that this research adopts the principle of voluntary participation, and all the collected data would be kept strictly confidential, and the survey is only for research purposes so no individual or organization can access the data except our researchers. Before filling out the survey questionnaires, all participants claimed that they understand the purpose of our survey research and agree to participate voluntarily.

\section{Acknowledgments}

All authors would like to gratitude the research fellows who participated in the data collection and analysis of the study. All authors have read and approved the final manuscript.

\section{Funding}

This work was supported by "the Fundamental Research Funds for the Central Universities, Zhongnan University of Economics and Law (Grant No. 2722020JCG059)", in part by the Young Scientists Fund of Humanities and social sciences of the Ministry of Education of China under Grant 19YJC630236, in part by the Young Scientists Fund of the National Natural Science Foundation of China under Grants 71802073 and 71802194, and in part by the Philosophy and social science research project of Hubei Provincial Department of Education under Grant 19Q093.

\section{Disclosure}

The authors report no conflicts of interest in this work. 


\section{References}

1. Morrison EW, Phelps CC. Taking charge at work: extrarole efforts to initiate workplace change. Acad Manage J. 1999;42(4):403-419.

2. Crant JM. Proactive behavior in organizations. J Manage. 2000;26 (3):435-462. doi:10.1177/014920630002600304

3. Parker SK, Williams HM, Turner N. Modeling the antecedents of proactive behavior at work. $J$ Appl Psychol. 2006;91(3):636. doi:10.1037/0021-9010.91.3.636

4. Yam KC, Klotz AC, He W, Reynolds SJ. From good soldiers to psychologically entitled: examining when and why citizenship behavior leads to deviance. Acad Manage J. 2017;60(1):373-396. doi:10.5465/amj.2014.0234

5. Bennett N, Lemoine J. What VUCA really means for you. Harv Bus Rev. 2014;92:1/2.

6. Tepper BJ, Lockhart D, Hoobler J. Justice, citizenship, and role definition effects. J Appl Psychol. 2001;86(4):789. doi:10.1037/ 0021-9010.86.4.789

7. Tepper BJ, Taylor EC. Relationships among supervisors' and subordinates' procedural justice perceptions and organizational citizenship behaviors. Acad Manage J. 2003;46(1):97-105.

8. Organ D, Podsakoff P, MacKenzie S. Organizational citizenship behavior: its nature, antecedents, and consequences. Thousand Oaks, California; 2006.

9. Foote DA, Tang TLP. Job satisfaction and organizational citizenship behavior (OCB). Manage Decision. 2008;46:933-947. doi:10.1108/ 00251740810882680

10. Yee RW, Yeung AC, Cheng TE. The impact of employee satisfaction on quality and profitability in high-contact service industries. $J$ Operations Manage. 2008;26(5):651-668. doi:10.1016/j.jom.2008.01.001

11. Bakker AB, Albrecht SL, Leiter MP. Work engagement: further reflections on the state of play. Eur J Work Organizational Psychol. 2011;20(1):74-88. doi:10.1080/1359432X.2010.546711

12. Paulin M, Ferguson RJ, Bergeron J. Service climate and organizational commitment: the importance of customer linkages. J Bus Res. 2006;59(8):906-915. doi:10.1016/j.jbusres.2006.03.004

13. Zheng W, Zhang M, Li H. Performance appraisal process and organizational citizenship behavior. $J$ Managerial Psychol. 2012;27:732-752. doi:10.1108/02683941211259548

14. Shaw JD, Dineen BR, Fang R, Vellella RF. Employee-organization exchange relationships, HRM practices, and quit rates of good and poor performers. Acad Manage J. 2009;52(5):1016-1033. doi:10.5465/amj.2009.44635525

15. Lomoya MG, Pingol MB, Teng-Calleja M. Antecedents of job satisfaction and organizational citizenship behaviors among agency-hired blue-collar contractual workers in the Philippines. Philipp. J. Psychol. 2015;48(1):1-27.

16. López-Domínguez M, Enache M, Sallan JM, Simo P. Transformational leadership as an antecedent of change-oriented organizational citizenship behavior. J Bus Res. 2013;66 (10):2147-2152. doi:10.1016/j.jbusres.2013.02.041

17. Bolino MC, Klotz AC. The paradox of the unethical organizational citizen: the link between organizational citizenship behavior and unethical behavior at work. Current Opinion Psychol. 2015;6:45-49. doi:10.1016/j.copsyc.2015.03.026

18. Li R, Zhang ZY, Tian XM. Can self-sacrificial leadership promote subordinate taking charge? The mediating role of organizational identification and the moderating role of risk aversion. J Organ Behav. 2016;37(5):758-781. doi:10.1002/job.2068

19. Vandyne L, Cummings LL, Parks JM. Extra-role behaviors-in pursuit of construct and definitional clarity (a bridge over muddied waters). Res Organizational Behav. 1995;17:215-285.

20. Podsakoff PM, MacKenzie SB, Paine JB, Bachrach DG. Organizational citizenship behaviors: a critical review of the theoretical and empirical literature and suggestions for future research. J Manage. 2000;26(3):513-563. doi:10.1177/014920630002600307
21. McAllister DJ, Kamdar D, Morrison EW, Turban DB. Disentangling role perceptions: how perceived role breadth, discretion, instrumentality, and efficacy relate to helping and taking charge. $J \mathrm{Appl}$ Psychol. 2007;92(5):1200. doi:10.1037/0021-9010.92.5.1200

22. Chiaburu DS, Oh I-S, Wang J, Stoverink AC. A bigger piece of the pie: the relative importance of affiliative and change-oriented citizenship and task performance in predicting overall job performance. Human Resource Manage Rev. 2017;27(1):97-107. doi:10.1016/j. hrmr.2016.09.006

23. Li N, Chiaburu DS, Kirkman BL. Cross-level influences of empowering leadership on citizenship behavior: organizational support climate as a double-edged sword. J Manage. 2017;43(4):1076-1102. doi:10.1177/0149206314546193

24. Liu H, Chiang -JT-J, Fehr R, Xu M, Wang S. How do leaders react when treated unfairly? Leader narcissism and self-interested behavior in response to unfair treatment. $J$ Appl Psychol. 2017;102(11):1590. doi:10.1037/ap10000237

25. Zhang X-A, Li N, Tb H. Putting non-work ties to work: the case of guanxi in supervisor-subordinate relationships. Leadersh Q. 2015;26 (1):37-54. doi:10.1016/j.leaqua.2014.04.008

26. Janssen O, Gao L. Supervisory responsiveness and employee self-perceived status and voice behavior. $J$ Manage. 2015;41 (7):1854-1872. doi:10.1177/0149206312471386

27. Anderson C, John OP, Keltner D, Kring AM. Who attains social status? Effects of personality and physical attractiveness in social groups. J Pers Soc Psychol. 2001;81(1):116. doi:10.1037/00223514.81.1.116

28. Chen Y-R, Peterson RS, Phillips DJ, Podolny JM, Ridgeway CL. Introduction to the special issue: bringing status to the table - attaining, maintaining, and experiencing status in organizations and markets. Informs. 2012.

29. Bandura A. The explanatory and predictive scope of self-efficacy theory. J Soc Clin Psychol. 1986;4(3):359-373. doi:10.1521/ jscp.1986.4.3.359

30. Christensen-Salem A, Walumbwa FO, Hsu -CI-C, Misati E, Babalola MT, Kim K. Unmasking the creative self-efficacy-creative performance relationship: the roles of thriving at work, perceived work significance, and task interdependence. Int J Human Resource Manage. 2020;1-27. doi:10.1080/09585192.2019.1710721

31. Spreitzer G, Sutcliffe K, Dutton J, Sonenshein S, Grant AM. A socially embedded model of thriving at work. Organization Sci. 2005;16(5):537-549. doi:10.1287/orsc. 1050.0153

32. Porath C, Spreitzer G, Gibson C, Garnett FG. Thriving at work: toward its measurement, construct validation, and theoretical refinement. J Organ Behav. 2012;33(2):250-275. doi:10.1002/ job. 756

33. Bandura A. Human agency in social cognitive theory. Am Psychologist. 1989;44(9):1175. doi:10.1037/0003-066X.44.9.1175

34. Anderson C, Hildreth JAD, Howland L. Is the desire for status a fundamental human motive? A review of the empirical literature. Psychol Bull. 2015;141(3):574. doi:10.1037/a0038781

35. Duguid MM, Loyd DL, Tolbert PS. The impact of categorical status, numeric representation, and work group prestige on preference for demographically similar others: a value threat approach. Organization Sci. 2012;23(2):386-401. doi:10.1287/orsc.1100.0565

36. De Cremer D, Tyler TR. Am I respected or not?: inclusion and reputation as issues in group membership. Soc Justice Res. 2005;18 (2):121-153. doi:10.1007/s11211-005-7366-3

37. Anderson C, Srivastava S, Beer JS, Spataro SE, Chatman JA. Knowing your place: self-perceptions of status in face-to-face groups. J Pers Soc Psychol. 2006;91(6):1094. doi:10.1037/00223514.91.6.1094

38. Blader SL, Chen Y-R. What influences how higher-status people respond to lower-status others? Effects of procedural fairness, outcome favorability, and concerns about status. Organization Sci. 2011;22(4):1040-1060. doi:10.1287/orsc.1100.0558 
39. Magee JC, Galinsky AD. 8 social hierarchy: the self-reinforcing nature of power and status. Acad Manage Ann. 2008;2(1):351-398. doi: $10.5465 / 19416520802211628$

40. Owens D, Sutton R. Meetings as Status Contests: negotiating order in on-going workgroups. 2001. Groups Work Adv Theory Res. 299-316. M. Turner, ed.

41. Kim TY, Liu Z, Diefendorff JM. Leader-member exchange and job performance: the effects of taking charge and organizational tenure. J Organ Behav. 2015;36(2):216-231. doi:10.1002/job.1971

42. Kim T-Y LZ. Taking charge and employee outcomes: the moderating effect of emotional competence. Int J Human Resource Manage. 2017;28(5):775-793. doi:10.1080/09585192.2015.1109537

43. Wood R, Bandura A. Social cognitive theory of organizational management. Acad Manage Rev. 1989;14(3):361-384. doi:10.5465/ amr.1989.4279067

44. Galperin BL, Bennett RJ, Aquino K. Status differentiation and the protean self: a social-cognitive model of unethical behavior in organizations. J Business Ethics. 2011;98(3):407-424. doi:10.1007/ s10551-010-0556-4

45. Thompson MN, Dahling JJ. Perceived social status and learning experiences in social cognitive career theory. J Vocat Behav. 2012;80(2):351-361. doi:10.1016/j.jvb.2011.10.001

46. Fuller JB, Hester K, Barnett T, Frey L, Relyea C, Beu D. Perceived external prestige and internal respect: new insights into the organizational identification process. Human Relations. 2006;59(6):815-846. doi:10.1177/0018726706067148

47. Deng C, Liao S, Liu Z. When does status turn into proactive helping behavior? The moderating role of cooperative/competitive behavior intention. Front Psychol. 2019;10:2702. doi:10.3389/ fpsyg.2019.02702

48. Bolino MC, Turnley WH. Measuring impression management in organizations: a scale development based on the Jones and Pittman taxonomy. Organizational Res Methods. 1999;2(2):187-206. doi:10.1177/109442819922005

49. Clary EG, Snyder M. The motivations to volunteer: theoretical and practical considerations. Curr Dir Psychol Sci. 1999;8(5):156-159. doi:10.1111/1467-8721.00037

50. Nowak MA. Five rules for the evolution of cooperation. Science (New York, N.Y.). 2006;314(5805):1560-1563. doi:10.1126/ science. 1133755

51. Lount JRB, Pettit NC. The social context of trust: the role of status. Organ Behav Hum Decis Process. 2012;117(1):15-23. doi:10.1016/j. obhdp.2011.07.005

52. Brandts J, Fatas E, Haruvy E, Lagos F. The impact of relative position and returns on sacrifice and reciprocity: an experimental study using individual decisions. Soc Choice Welfare. 2015;45 (3):489-511. doi:10.1007/s00355-014-0818-7

53. Anderson C, Willer R, Kilduff GJ, Brown CE. The origins of deference: when do people prefer lower status? J Pers Soc Psychol. 2012;102(5):1077. doi:10.1037/a0027409

54. Flynn FJ. How much should I give and how often? The effects of generosity and frequency of favor exchange on social status and productivity. Acad Manage J. 2003;46(5):539-553.

55. Torelli CJ, Leslie LM, Stoner JL, Puente R. Cultural determinants of status: implications for workplace evaluations and behaviors. Organ Behav Hum Decis Process. 2014;123(1):34-48. doi:10.1016/j. obhdp.2013.11.001

56. Kark R, Carmeli A. Alive and creating: the mediating role of vitality and aliveness in the relationship between psychological safety and creative work involvement. J Organizational Behav. 2009;30 (6):785-804. doi:10.1002/job.571

57. Ryan RM, Frederick C. On energy, personality, and health: subjective vitality as a dynamic reflection of well-being. J Pers. 1997;65 (3):529-565. doi:10.1111/j.1467-6494.1997.tb00326.x
58. Dutton JE, Heaphy ED. The power of high-quality connections. Positive Organizational Scholarship Foundations New Discipline. 2003;3:263-278.

59. Feldman F. Pleasure and the Good Life: Concerning the Nature, Varieties, and Plausibility of Hedonism. Oxford University Press on Demand; 2004.

60. Dutton J, Frost P, Kanov J, Lilius J, Maitlis S, Worline M. Helping your workplace heal. Leading in Trying Times website, University of Michigan, Ann Arbor MI; 2005. Available from: http://www.bus. umich.edu/FacultyResearch/Research/TryingTimes/Heal.htm. Accessed September 7, 2005.

61. Reis HT, Gable SL. Toward a positive psychology of relationships. In: Flourishing: Positive psychology and the life well-lived. Washington, DC, US: American Psychological Association; 2003:129-159.

62. Ryan R, Bernstein J. Vitality. Character Strengths and Virtues: A Handbook and Classification. 2004:273-290.

63. Shraga O, Shirom A. The construct validity of vigor and its antecedents: a qualitative study. Human Relations. 2009;62(2):271-291. doi: $10.1177 / 0018726708100360$

64. Shirom A. Vigor as a positive affect at work: conceptualizing vigor, its relations with related constructs, and its antecedents and consequences. Rev General Psychol. 2011;15(1):50-64. doi:10.1037/a0021853

65. Shirom A. Burnout and health: expanding our knowledge. Stress and Health: Journal of the International Society for the Investigation of Stress. 2009;25(4):281-285.

66. Kleine AK, Rudolph CW, Zacher H. Thriving at work: a metaanalysis. J Organ Behav. 2019;40(9-10):973-999. doi:10.1002/ job. 2375

67. Parker SK, Collins CG. Taking stock: integrating and differentiating multiple proactive behaviors. $J$ Manage. 2010;36(3):633-662. doi: $10.1177 / 0149206308321554$

68. Hobfoll SE. The influence of culture, community, and the nested-self in the stress process: advancing conservation of resources theory. Appl Psychol. 2001;50(3):337-421. doi:10.1111/1464-0597.00062

69. Sidanius J, Pratto F. Social dominance theory: anew synthesis. New York, NY, US: Psychology Press; 2004.

70. Pratto F, Sidanius J, Levin S. Social dominance theory and the dynamics of intergroup relations: taking stock and looking forward. Eur Rev Social Psychol. 2006;17(1):271-320. doi:10.1080/ 10463280601055772

71. Hodson G, Rush J, MacInnis CC. A joke is just a joke (except when it isn't): cavalier humor beliefs facilitate the expression of group dominance motives. J Pers Soc Psychol. 2010;99(4):660. doi:10.1037/a0019627

72. Jackman MR. The velvet glove: paternalism and conflict in gender, class, and race relations. Univ of California Press; 1994.

73. Pratto F, Sidanius J, Stallworth LM, Malle BF. Social dominance orientation: a personality variable predicting social and political attitudes. J Pers Soc Psychol. 1994;67(4):741. doi:10.1037/00223514.67.4.741

74. Haley H, Sidanius J. Person-organization congruence and the maintenance of group-based social hierarchy: a social dominance perspective. Group Processes Intergroup Relations. 2005;8 (2):187-203. doi:10.1177/1368430205051067

75. Kenrick DT, Griskevicius V, Neuberg SL, Schaller M. Renovating the pyramid of needs: contemporary extensions built upon ancient foundations. Perspect Psychol Sci. 2010;5(3):292-314. doi:10.1177/ 1745691610369469

76. Maner JK, Mead NL. The essential tension between leadership and power: when leaders sacrifice group goals for the sake of self-interest. J Pers Soc Psychol. 2010;99(3):482. doi:10.1037/ a0018559 
77. Maner JK, Case CR. Dominance and prestige: dual strategies for navigating social hierarchies. Adv Exp Soc Psychol. 2016;54:129-180.

78. Keltner D, Gruenfeld DH, Anderson C. Power, approach, and inhibition. Psychol Rev. 2003;110(2):265. doi:10.1037/0033295X.110.2.265

79. Islam G, Zyphur MJ. Power, voice, and hierarchy: exploring the antecedents of speaking up in groups. Group Dynamics Theory, Res Practice. 2005;9(2):93. doi:10.1037/1089-2699.9.2.93

80. de Lange AH, Van Yperen NW, Van der Heijden BI, Bal PM. Dominant achievement goals of older workers and their relationship with motivation-related outcomes. J Vocat Behav. 2010;77 (1):118-125. doi:10.1016/j.jvb.2010.02.013

81. Cassidy T, Lynn R. A multifactorial approach to achievement motivation: the development of a comprehensive measure. J Occup Psychol. 1989.

82. Podsakoff PM, MacKenzie SB, Lee J-Y, Podsakoff NP. Common method biases in behavioral research: a critical review of the literature and recommended remedies. J Appl Psychol. 2003;88(5):879. doi:10.1037/0021-9010.88.5.879

83. Brislin RW. The wording and translation of research instruments; 1986.

84. Spreitzer G, Porath CL, Gibson CB. Toward human sustainability: how to enable more thriving at work. Organ Dyn. 2012;41 (2):155-162. doi:10.1016/j.orgdyn.2012.01.009

85. Lee HW, Bradburn J, Johnson RE, Lin S-HJ, Chang C-HD. The benefits of receiving gratitude for helpers: a daily investigation of proactive and reactive helping at work. J Appl Psychol. 2019;104 (2):197. doi:10.1037/ap10000346
86. Detert JR, Burris ER. Leadership behavior and employee voice: is the door really open? Acad Manage J. 2007;50(4):869-884. doi:10.5465/ amj.2007.26279183

87. Kalshoven K, van Dijk H, Boon C. Why and when does ethical leadership evoke unethical follower behavior? J Managerial Psychol. 2016;31(2):500-515. doi:10.1108/JMP-10-2014-0314

88. Sabherwal R, Becerra-Fernandez I. An empirical study of the effect of knowledge management processes at individual, group, and organizational levels. Decision Sci. 2003;34(2):225-260. doi:10.1111/ 1540-5915.02329

89. Hayes AF. Introduction to mediation, moderation, and conditional process analysis: a regression-based approach. Guilford Publications; 2017.

90. Baron RM, Kenny DA. The moderator-mediator variable distinction in social psychological research: conceptual, strategic, and statistical considerations. J Pers Soc Psychol. 1986;51(6):1173. doi:10.1037/ 0022-3514.51.6.1173

91. Hayes AF. Methodology in the social sciences. Introduction to mediation, moderation, and conditional process analysis: a regression-based approach. NY: Guilford Press New York; 2013.

92. Carpenter NC, Berry CM, Houston L. A meta-analytic comparison of self-reported and other-reported organizational citizenship behavior. J Organ Behav. 2014;35(4):547-574. doi:10.1002/job.1909

93. Otaye-Ebede L, Shaffakat S, Foster S. A multilevel model examining the relationships between workplace spirituality, ethical climate and outcomes: a social cognitive theory perspective. $J$ Business Ethics. 2020;166(3):611-626. doi:10.1007/s10551-019-04133-8
Psychology Research and Behavior Management

\section{Publish your work in this journal}

Psychology Research and Behavior Management is an international, peer-reviewed, open access journal focusing on the science of psychology and its application in behavior management to develop improved outcomes in the clinical, educational, sports and business arenas. Specific topics covered in the journal include: Neuroscience, memory and decision making; Behavior modification and management; Clinical applications; Business and sports performance management; Social and developmental studies; Animal studies. The manuscript management system is completely online and includes a very quick and fair peer-review system, which is all easy to use. Visit http://www. dovepress.com/testimonials.php to read real quotes from published authors. 